\title{
Erratum: Electro-Optic Properties of PLZT Thick-Film on Glass Substrate with Embedded Electrodes Structure
}

\author{
[J. Korean Phys. Soc. 42, S1310 (2003)] \\ Jong-Jin ChOI, Dal-Young Kim, ${ }^{*}$ Gun-Tae PARK and Hyoun-Ee KIM \\ School of Materials Science and Engineering, Seoul National University, Seoul 151-742, Korea \\ DOI: $10.3938 /$ jkps.60.894
}

Figure 2 was submitted incorrectly. It should be corrected as below;

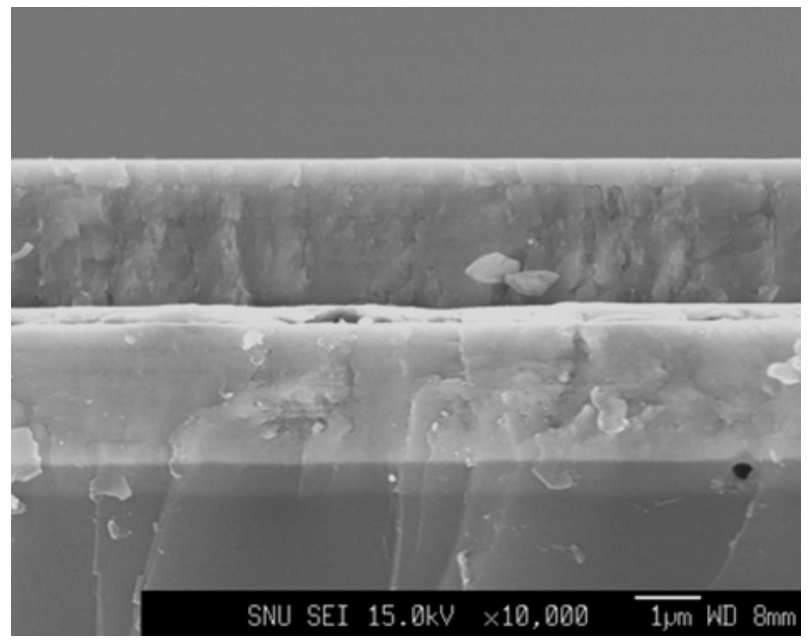

*E-mail: dykim@seoultech.ac.kr

Present address: Department of Optometry, Seoul Tech, Seoul 139-743, Korea 